\title{
Mental Disorders and Mental Health Service Use Across Asian American Subethnic Groups in the United States
}

\author{
Su Yeon Lee $\cdot$ Silvia S. Martins $\cdot$ Hochang B. Lee
}

Received: 1 February 2013/ Accepted: 16 June 2014/Published online: 24 June 2014

(C) Springer Science+Business Media New York 2014

\begin{abstract}
This study analyzed the National Epidemiological Survey on Alcohol and Related Conditions data, 2001-2002, to compare the prevalence and odds of DSMIV mood, anxiety, and substance use disorders and mental health service use across Asian American subethnic groups (648 East Asians, 485 Southeast Asians, 298 South Asians). Asian American subethnic groups varied in lifetime prevalence of psychiatric disorders $(p=0.004)$, mainly due to differences in the presence of any substance use disorder $(p=0.06)$, and specifically, drug use disorders $(p=0.02)$. While Southeast Asians had the highest prevalence of substance use disorders $(16.7 \%)$, fewer Southeast Asians with substance use disorders used mental health services $(11.1 \%)$ compared to South Asians with substance use disorders (24.2\%). East Asians compared to South Asians had significantly lower odds of mental health service use for substance use disorders (confidence inter$\mathrm{val}=0.08-0.84$ ). Asian American subethnic groups vary in the prevalence of mental disorders and in mental health service use, especially for substance use disorders.
\end{abstract}

S. Y. Lee $(\bowtie)$

Johns Hopkins Bloomberg School of Public Health, 624 N.

Broadway, 8th Floor, Baltimore, MD 21205, USA

e-mail: slee226@jhu.edu

S. S. Martins

Department of Epidemiology, Columbia University Mailman

School of Public Health, 722 West 168th Street, Rm. 509,

New York, NY 10032, USA

H. B. Lee

Psychological Medicine Service, Yale New Haven Hospital, Yale University School of Medicine, 20 York St., CB 2039, New Haven, CT 06510, USA
Keywords Asian Americans - Subethnic groups - DSMIV psychiatric disorders - Mental health service use

\section{Introduction}

Persons of Asian ancestry are the fastest growing ethnic minority group in the United States (U.S. Census Bureau 2011). In 2010, Asian Americans comprised $5 \%$ of the total United States population, a proportion that is projected to increase to $10 \%$ in 2050 (Humes et al. 2011). Asian Americans are a culturally and linguistically diverse group in the United States, representing 43 ethnic groups and speaking over a hundred different languages (U.S. Department of Health and Human Services 2001). Despite the growing number and diversity of Asian Americans, previously published studies on mental health needs and service use among persons of Asian ancestry tended to treat Asian Americans as a homogeneous category and have not assessed the differences across the Asian American subethnic groups (Gee et al. 2007; Lee et al. 2011; Xu et al. 2011).

Asian American subethnic groups differ in various socioeconomic and cultural factors associated with mental health service use, such as mental health needs, attitudes towards mental health, awareness and access to culturally appropriate services, English proficiency, and severity of mental disorders (Anderson and John 1973). South Asians have generally had lower lifetime and past year prevalence of mood, anxiety, and substance use disorders when compared to the rest of Asian Americans (Masood et al. 2009). Non-elderly Vietnamese and Korean Americans have the highest uninsurance rates of $21 \%$ and $31 \%$ among Asian American adults, respectively, compared to an uninsurance rate of $12 \%$ among Japanese and Indian Americans (The Kaiser Family Foundation 2008). Limited English 
proficiency is associated with lower use of mental health services (Sentell et al. 2007), and the National Latino and Asian American Study (NLAAS) found that only $3.1 \%$ of South Asians and $4.6 \%$ of Filipinos had limited English proficiency while $46.9 \%$ of Koreans and $51.8 \%$ of Vietnamese reported difficulty speaking English (Gee et al. 2007).

Only a small number of studies compared Asian American subethnic group differences in mental health service use (Abe-Kim et al. 2007; Akutsu et al. 2007; Hu et al. 1993; Tiwari and Wang 2008). For example, despite the availability of publicly funded mental health services in Canada, prevalence of mental health service use among Chinese $(26.1 \%)$ and Southeast Asians (26.1\%) with major depressive disorder were significantly lower than service use among South Asians (37.5\%) with major depressive disorder (Tiwari and Wang 2008). In the United States, Abe-Kim and colleagues found that compared to Filipinos, Chinese significantly underused medical services for mental health treatment when adjustment was made for age and the presence of mental disorders (Abe-Kim et al. 2007). Chinese and Vietnamese had lower prevalence of subjective satisfaction and perceived helpfulness regarding mental health care compared to Filipino Americans and other Asians (including Japanese, Korean, Asian Indian, and other Asian ethnicities) (Abe-Kim et al. 2007). To our knowledge, no previous study has stratified the analysis of mental health service use across Asian American subethnic groups by types of mental disorders.

A study using the National Epidemiological Survey on Alcohol and Related Conditions (NESARC) reported that Asians with mood disorders particularly underused mental health services compared to whites, Hispanics, and Native Americans (Lee et al. 2011). However, it remains unclear whether or not all Asian American subethnic groups share the same characteristics in mental health needs and service use. It is important to identify subethnic groups with greater disparities in mental health needs and care, in order to develop targeted interventions that strengthen the pathways to accessing mental health services. The goal of this study was to examine the differences in the mental health needs and patterns of mental health service use across the three Asian American subethnic groups (East Asian, Southeast Asian, and South Asian) using a large-scale dataset, the NESARC.

\section{Methods}

Sample

The study participants were the Asian subsample $(n=1,431)$ of the NESARC wave one identified by their reported countries of origin (2001-2002; $\mathrm{N}=43,093)$. The NESARC is a community-based, epidemiological survey of adults over 18 years of age with an overall response rate of $81 \%$ (Grant et al. 2003). NESARC is sponsored by the National Institute on Alcohol Abuse and Alcoholism (NIAAA) and conducted by the U.S. Census Bureau. The Office of Management and Budget reviewed and approved the research protocol and the informed consent. Detailed study methodology of the NESARC is described elsewhere (Grant et al. 2003a, 2003b, 2005).

For the purpose of this study, Asian participants were classified by participants' countries of origin or descent based on the United Nations Statistics Division's geographic region and composition guidelines (Division 2011), into East Asians $(n=648)$, Southeast Asians $(n=485)$, and South Asians $(n=298)$. A total of 648 East Asians were identified based on participants' country of origin being China $(n=306)$, Japan $(n=175)$, Korea $(n=131)$, and Taiwan $(n=36)$. A total of 485 Southeast Asians consisted of participants from Indonesia $(n=29)$, Malaysia $(\mathrm{n}=11)$, Vietnam $(\mathrm{n}=101)$, Thai, Laos, Cambodia, and Burma $(\mathrm{n}=82)$, and the Pacific Islands $(\mathrm{n}=39)$. South Asians $(\mathrm{n}=298)$ included individuals originally from India, Afghanistan, Pakistan $(\mathrm{n}=251)$ and Iran $(n=47)$.

\section{Measures}

\section{DSM-IV Diagnosis}

Trained lay interviewers administered a structured psychiatric interview to all participants, the NIAAA Alcohol Use Disorder and Associated Disabilities Interview Schedule-DSM-IV (AUDADIS-IV). The AUDADIS-IV was designed to assess DSM-IV based mood disorders, alcohol disorders, and substance use in large scale surveys (American Psychiatric Association 1994). Mood disorders consisted of major depressive disorder, dysthymia, and bipolar disorder type I and II. Anxiety disorders included social phobia, generalized anxiety disorder, agoraphobia with or without panic disorder, and specific phobias. Mood and anxiety disorders triggered by substance use or physical illness were not included. Substance use disorders included alcohol abuse/dependence or drug abuse/dependence. Drug use disorders included the use of sedatives, tranquilizers, opiates, stimulants, hallucinogens, cannabis, cocaine, inhalants or solvents, heroin, and other drugs. Reliability and validity of the AUDADIS-IV mood disorders, anxiety disorders, and substance use disorders among multiracial samples are published elsewhere (Grant et al. 2004, 2005; Ruan et al. 2008). 
Table 1 Descriptive

characteristics of Asian

American subethnic group participants $(\mathrm{n}=1,431)$ in wave 1 of the NESARC

\begin{tabular}{|c|c|c|c|c|c|c|c|c|c|c|c|c|}
\hline \multirow[t]{3}{*}{ Characteristic } & \multirow{2}{*}{\multicolumn{3}{|c|}{$\begin{array}{l}\text { East Asians } \\
(\mathrm{N}=648)\end{array}$}} & \multirow{2}{*}{\multicolumn{3}{|c|}{$\begin{array}{l}\text { Southeast } \\
\text { Asians } \\
(\mathrm{N}=485)\end{array}$}} & \multirow{2}{*}{\multicolumn{3}{|c|}{$\begin{array}{l}\text { South Asians } \\
(\mathrm{N}=298)\end{array}$}} & \multirow[t]{3}{*}{$\chi^{2}$} & \multirow[t]{3}{*}{$\mathrm{df}$} & \multirow[t]{3}{*}{$p$} \\
\hline & & & & & & & & & & & & \\
\hline & $\mathrm{N}$ & $\%$ & SE & $\mathrm{N}$ & $\%$ & $\mathrm{SE}$ & $\mathrm{N}$ & $\%$ & SE & & & \\
\hline Sex & & & & & & & & & & 8.3 & 2 & $0.02 *$ \\
\hline Male & 276 & 42.6 & 1.9 & 208 & 42.9 & 2.2 & 155 & 52.0 & 4.0 & & & \\
\hline Female & 372 & 57.4 & 1.9 & 277 & 57.1 & 2.2 & 143 & 48.0 & 4.0 & & & \\
\hline Age (years) & & & & & & & & & & 16.0 & 10 & 0.10 \\
\hline $18-24$ & 107 & 16.5 & 1.4 & 83 & 17.1 & 1.7 & 42 & 14.1 & 2.0 & & & \\
\hline $25-34$ & 152 & 23.5 & 1.7 & 111 & 22.9 & 1.9 & 86 & 28.9 & 2.6 & & & \\
\hline $35-44$ & 133 & 20.5 & 2.1 & 121 & 25.0 & 2.5 & 82 & 27.5 & 2.8 & & & \\
\hline $45-54$ & 118 & 18.2 & 1.5 & 76 & 15.7 & 1.7 & 44 & 14.8 & 2.1 & & & \\
\hline $55-64$ & 63 & 9.7 & 1.2 & 47 & 9.7 & 1.3 & 21 & 7.1 & 1.5 & & & \\
\hline$>65$ & 75 & 11.6 & 1.2 & 47 & 9.7 & 1.3 & 23 & 7.7 & 1.5 & & & \\
\hline Years in United States & & & & & & & & & & 44.8 & 6 & $<0.01 * *$ \\
\hline Entire life & 200 & 30.9 & 1.8 & 149 & 30.7 & 2.1 & 60 & 20.1 & 2.3 & & & \\
\hline$\geq 20$ & 144 & 22.2 & 1.6 & 76 & 15.7 & 1.6 & 102 & 34.2 & 2.8 & & & \\
\hline $10-19$ & 130 & 20.1 & 1.6 & 120 & 24.7 & 2.0 & 72 & 24.2 & 2.5 & & & \\
\hline$<10$ & 174 & 26.9 & 1.7 & 140 & 28.9 & 2.1 & 64 & 21.5 & 2.4 & & & \\
\hline Family income & & & & & & & & & & 12.5 & 6 & 0.05 \\
\hline$\$ 1,000-19,999$ & 151 & 23.3 & 1.7 & 121 & 25.0 & 2.0 & 64 & 21.5 & 2.4 & & & \\
\hline$\$ 20,000-34,999$ & 133 & 20.5 & 1.6 & 91 & 18.8 & 1.8 & 54 & 18.1 & 2.2 & & & \\
\hline$\$ 35,000-69,999$ & 187 & 28.9 & 1.8 & 163 & 33.6 & 2.9 & 81 & 21.2 & 2.6 & & & \\
\hline$\$ 70,000+$ & 177 & 27.3 & 1.8 & 110 & 22.7 & 1.9 & 99 & 33.2 & 2.8 & & & \\
\hline Occupation & & & & & & & & & & 32.0 & 6 & $<0.001 * * *$ \\
\hline $\begin{array}{l}\text { Administrative/ } \\
\text { professional }\end{array}$ & 296 & 45.7 & 2.2 & 220 & 45.4 & 2.5 & 146 & 49.0 & 3.2 & & & \\
\hline Services/sales & 148 & 22.8 & 2.1 & 132 & 27.2 & 2.3 & 61 & 20.5 & 2.9 & & & \\
\hline $\begin{array}{l}\text { Transportation/ } \\
\text { equipment/other } \\
\text { laborers }\end{array}$ & 44 & 6.8 & 1.3 & 64 & 13.2 & 1.8 & 26 & 8.7 & 2.1 & & & \\
\hline $\begin{array}{l}\text { Never worked for } \\
\text { salary }\end{array}$ & 160 & 24.7 & 1.7 & 69 & 14.2 & 1.6 & 65 & 21.8 & 2.4 & & & \\
\hline Education & & & & & & & & & & 52.8 & 6 & $<0.001 * * *$ \\
\hline Less than high school & 60 & 9.3 & 1.1 & 80 & 16.5 & 1.7 & 32 & 10.7 & 1.8 & & & \\
\hline High school & 114 & 17.6 & 1.5 & 107 & 22.1 & 1.9 & 55 & 18.5 & 2.3 & & & \\
\hline Some college & 115 & 17.8 & 1.5 & 107 & 22.1 & 1.9 & 29 & 9.7 & 1.7 & & & \\
\hline College graduate & 359 & 55.4 & 2.0 & 191 & 39.4 & 2.2 & 182 & 61.1 & 2.8 & & & \\
\hline Urbanicity & & & & & & & & & & 6.7 & 2 & $0.04 *$ \\
\hline Urban residency & 308 & 50.5 & 2.0 & 197 & 44.8 & 2.4 & 118 & 42.0 & 2.9 & & & \\
\hline Region & & & & & & & & & & 110.7 & 6 & $<0.001 * * *$ \\
\hline Northeast & 155 & 23.9 & 1.7 & 51 & 10.5 & 1.4 & 81 & 27.2 & 2.6 & & & \\
\hline Midwest & 55 & 8.5 & 1.1 & 72 & 14.9 & 1.6 & 39 & 13.1 & 2.0 & & & \\
\hline South & 110 & 17.0 & 1.5 & 94 & 19.4 & 1.8 & 101 & 33.9 & 2.7 & & & \\
\hline West & 328 & 50.6 & 2.0 & 268 & 55.3 & 2.3 & 77 & 25.8 & 2.5 & & & \\
\hline Insurance & & & & & & & & & & 2.4 & 2 & 0.30 \\
\hline No (i.e. uninsured) & 154 & 23.8 & 1.7 & 97 & 20.0 & 1.8 & 69 & 23.2 & 2.4 & & & \\
\hline
\end{tabular}

$* p<0.05, * * p<0.01$, *** $p<0.001$

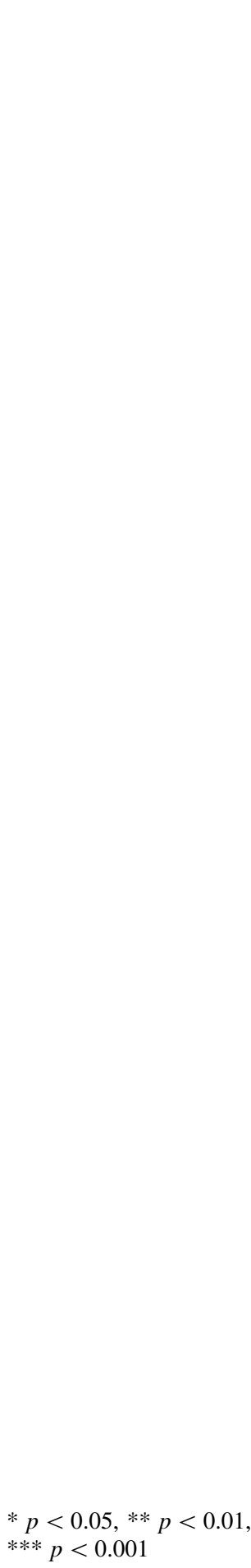




\section{Mental Health Service Use}

All respondents who screened positive for psychiatric symptoms based on the AUDADIS-IV reported their lifetime mental health service use for each psychiatric disorder. Mental health service utilization for those with mood and anxiety disorders included outpatient (physician, counselor, therapist, or other professional), inpatient (staying overnight or longer in the hospital setting), emergency room, or prescribed medicine use. Mental health service use for substance use disorders included seeking help from Narcotics Anonymous, Cocaine Anonymous, or 12-step meetings; social services for alcohol or drug detoxification wards; inpatient wards of psychiatric or general hospitals or community mental health programs; emergency services for alcohol or drug use; halfway houses or therapeutic communities; crisis centers related to substance use; and private physicians, psychiatrists, psychologists, social workers, or other professionals. Visits to clergy were not considered mental health service use, since we focused the analysis on outcome-based, formal mental health services.

\section{Statistical Analysis}

The comparison of the prevalence and odds of mental health service use among Asian American subethnic groups was based on the unweighted data, since the weights were used in NESARC for the generalizability of race and ethnicity defined broadly (Whites, Blacks, Hispanics, Asians, and Native Americans) rather than for Asian American subethnic groups in the United States. Data were analyzed with Stata/SE version 11.0. Descriptive statistics of the Asian sample were provided on sex, age, years lived in the United States, family income, education, occupation, urbanicity, region of residency, and health insurance status using cross tabulations (Table 1). Prevalence and standard errors of mental disorders and mental health service use among Asians with specific disorders were assessed with cross-tabulations and the proportion command. Asian American subethnic group differences in the prevalence of mental disorders were calculated with Chi squared statistics. Fisher's exact test was used to test for the difference in proportions of mental health service use by different Asian American subethnic groups to account for small cell counts. Multivariable logistic regression was used to assess subethnic group differences in the odds of mental health service use by mental disorder category, adjusting for age, sex, education, and current health insurance status.

\section{Results}

Demographic Variables

Table 1 displays significant differences in sex, number of years lived in the United States, occupation, education, urban residency, and region by racial/ethnic groups and not for age and health insurance status. South Asians were more likely to be male $(52.0 \%)$ compared to East Asians $(42.6 \%)$ and Southeast Asians (42.9\%; $p=0.02)$. While East Asians (30.9\%) and Southeast Asians (30.7\%) were more likely to have lived in the United States for their entire life than South Asians (20.1\%), South Asians were more likely to have lived in the United States for over 20 years $(34.2 \%$ compared to $22.2 \%$ among East Asians and $15.7 \%$ Southeast Asians) and were less likely to have lived in the United States for under 10 years $(21.5 \%$ compared to $26.9 \%$ among East Asians and $28.9 \%$ among Southeast Asians; $p<0.001)$. South Asians were most likely to hold an administrative or professional occupation (49.0\%), and Southeast Asians were more likely to work in services, sales, transportation, equipment, or other labor industry. East Asians had the highest proportion of residing in urban areas $(50.5 \%)$, followed by Southeast Asians $(44.8 \%)$. More than half of East Asians and Southeast Asians resided in the western region of the United States, while the highest proportion of South Asians lived in the southern region of the U.S (33.9\%). Over fifty-five percent of South Asians and East Asians were college graduates, compared to $39.4 \%$ of Southeast Asians $(p<0.001)$. Age and insurance status were not statistically significantly different between Asian American subethnic groups, and family income varied by Asian subethnic groups with marginal significance.

\section{Comparison of Mental Disorders Among Asian American Subethnic Groups}

Comparison of lifetime prevalence of mental disorders showed significant subethnic group differences in any DSM-IV psychiatric disorders among Asian Americans, influenced by significant differences in the prevalence of any substance use disorder (Table 2). Southeast Asians had a higher prevalence of any DSM-IV psychiatric disorders (34.6\%) compared to East Asians (22.5\%) and South Asians $(24.5 \% ; p<0.001)$. South Asians had the lowest prevalence of substance use disorders $(11.1 \%)$ followed by East Asians (13.1\%; $p=0.06)$. Southeast Asians had the highest prevalence of substance use disorders (16.7\%), mainly due to their higher prevalence of drug use disorders (15.5\%) compared to East Asians (10.2\%) and South 
Table 2 Lifetime prevalence of mental disorders among Asian American subethnic groups

\begin{tabular}{|c|c|c|c|c|c|c|c|c|c|c|c|c|}
\hline \multirow[t]{2}{*}{ Mental disorder } & \multicolumn{3}{|c|}{$\begin{array}{l}\text { East Asians } \\
(\mathrm{n}=648)\end{array}$} & \multicolumn{3}{|c|}{$\begin{array}{l}\text { Southeast Asians } \\
(\mathrm{n}=485)\end{array}$} & \multicolumn{3}{|c|}{$\begin{array}{l}\text { South Asians } \\
(\mathrm{n}=298)\end{array}$} & \multirow[t]{2}{*}{$\chi^{2}$} & \multirow[t]{2}{*}{ df } & \multirow[t]{2}{*}{$p$} \\
\hline & $\mathrm{N}$ & $\%$ & SE & $\mathrm{N}$ & $\%$ & SE & $\mathrm{N}$ & $\%$ & SE & & & \\
\hline \multicolumn{13}{|l|}{$\%$} \\
\hline \multicolumn{13}{|l|}{ Mood disorders } \\
\hline Major depression & 72 & 11.1 & 1.2 & 59 & 12.2 & 1.5 & 30 & 10.1 & 1.7 & 0.8 & 2 & 0.66 \\
\hline Dysthymia & 15 & 2.3 & 0.6 & 18 & 3.7 & 0.9 & 7 & 2.4 & 0.9 & 2.3 & 2 & 0.34 \\
\hline Bipolar disorder (I/II) & 25 & 3.8 & 0.8 & 30 & 6.2 & 1.1 & 14 & 4.7 & 1.2 & 3.3 & 2 & 0.19 \\
\hline Any mood disorder & 87 & 13.4 & 1.3 & 82 & 16.9 & 1.7 & 39 & 13.1 & 2.0 & 3.3 & 2 & 0.19 \\
\hline \multicolumn{13}{|l|}{ Anxiety disorder } \\
\hline Social phobia & 27 & 4.2 & 0.8 & 20 & 4.1 & 0.9 & 8 & 2.7 & 0.9 & 1.4 & 2 & 0.5 \\
\hline $\begin{array}{l}\text { Generalized anxiety } \\
\text { disorder }\end{array}$ & 17 & 2.6 & 0.6 & 10 & 2.1 & 0.6 & 6 & 2.0 & 0.8 & 0.5 & 2 & 0.77 \\
\hline $\begin{array}{l}\text { Agoraphobia or panic } \\
\text { disorder }\end{array}$ & 16 & 2.4 & 0.6 & 16 & 3.3 & 0.8 & 11 & 3.7 & 1.10 & 1.3 & 2 & 0.53 \\
\hline Specific phobia & 40 & 6.2 & 0.9 & 38 & 7.8 & 1.2 & 19 & 6.4 & 1.40 & 1.3 & 2 & 0.52 \\
\hline Any anxiety disorder & 74 & 11.4 & 1.2 & 65 & 13.4 & 1.5 & 34 & 11.4 & 1.80 & 1.2 & 2 & 0.55 \\
\hline \multicolumn{13}{|l|}{ Substance use disorder } \\
\hline Alcohol disorder & 35 & 5.4 & 0.01 & 21 & 4.3 & 0.01 & 8 & 2.7 & 0.01 & 3.6 & 2 & 0.17 \\
\hline Drug disorder & 66 & 10.2 & 0.01 & 75 & 15.5 & 0.02 & 31 & 10.4 & 0.02 & 8.2 & 2 & $0.02 *$ \\
\hline $\begin{array}{l}\text { Any substance use } \\
\text { disorder }\end{array}$ & 85 & 13.1 & 0.01 & 81 & 16.7 & 0.02 & 33 & 11.1 & 0.02 & 5.5 & 2 & 0.06 \\
\hline $\begin{array}{l}\text { Any DSM-IV psychiatric } \\
\text { disorder }\end{array}$ & 178 & 22.5 & 0.02 & 168 & 34.6 & 0.02 & 73 & 24.5 & 0.02 & 11.0 & 2 & $0.004 *$ \\
\hline
\end{tabular}

\begin{tabular}{|c|c|c|c|c|c|c|c|c|c|c|}
\hline \multirow[t]{3}{*}{ Mental disorder } & \multirow{2}{*}{\multicolumn{3}{|c|}{$\frac{\text { East Asian }}{(\mathrm{N}=648)}$}} & \multirow{2}{*}{\multicolumn{3}{|c|}{$\begin{array}{l}\text { Southeast Asian } \\
(\mathrm{N}=485)\end{array}$}} & \multirow{2}{*}{\multicolumn{3}{|c|}{$\frac{\text { South Asian }}{(\mathrm{N}=298)}$}} & \multirow[t]{3}{*}{$p$} \\
\hline & & & & & & & & & & \\
\hline & $\begin{array}{l}\text { Total } \\
\mathrm{N}\end{array}$ & $\begin{array}{l}\mathrm{N} \text { used } \\
\text { services }\end{array}$ & $\%$ & $\begin{array}{l}\text { Total } \\
\mathrm{N}\end{array}$ & $\begin{array}{l}\mathrm{N} \text { used } \\
\text { services }\end{array}$ & $\%$ & $\begin{array}{l}\text { Total } \\
\mathrm{N}\end{array}$ & $\begin{array}{l}\mathrm{N} \text { used } \\
\text { services }\end{array}$ & $\%$ & \\
\hline \multicolumn{11}{|l|}{$\%$} \\
\hline Any mood disorder & 87 & 33 & 37.9 & 82 & 30 & 36.6 & 39 & 16 & 41.0 & 0.9 \\
\hline $\begin{array}{l}\text { Any anxiety } \\
\text { disorder }\end{array}$ & 74 & 20 & 27.0 & 65 & 14 & 21.5 & 34 & 10 & 29.4 & 0.63 \\
\hline $\begin{array}{l}\text { Any substance use } \\
\text { disorder }\end{array}$ & 85 & 8 & 9.4 & 81 & 9 & 11.1 & 33 & 8 & 24.2 & 0.09 \\
\hline $\begin{array}{l}\text { Any DSM-IV } \\
\text { psychiatric } \\
\text { disorder }\end{array}$ & 178 & 51 & 28.7 & 168 & 42 & 25.0 & 73 & 22 & 30.1 & 0.81 \\
\hline
\end{tabular}

Table 3 Lifetime prevalence of mental health service use among Asian American subethnic groups $(\mathrm{N}=1,443)$ with specific mental disorders*

* Fisher's exact test calculated the $p$ value mental health service use. Only 8 or 9 individuals out of 85 East Asians (9.4\%), 81 Southeast Asians (11.1\%) and 33 South Asians (24.2\%) with substance use disorders received treatment $(p=0.09)$. While not statistically significant, South Asians with any DSM-IV psychiatric disorders (including mood, anxiety, and substance use disorders) were more likely to have used mental health services, compared to East Asians and Southeast Asians. There were no other statistically significant differences in the prevalence of mental disorders across Asian American subethnic groups. 
Table 4 Comparison of lifetime utilization of mental health services for Asian American subethnic groups with mental disorders*

\begin{tabular}{|c|c|c|c|c|c|c|c|c|}
\hline \multirow[t]{2}{*}{ Comparison } & \multicolumn{2}{|c|}{ Mood disorder } & \multicolumn{2}{|c|}{ Anxiety disorder } & \multicolumn{2}{|c|}{ Substance use disorder } & \multicolumn{2}{|c|}{ Any disorder } \\
\hline & OR & $95 \% \mathrm{CI}$ & OR & $95 \% \mathrm{CI}$ & OR & $95 \% \mathrm{CI}$ & OR & $95 \% \mathrm{CI}$ \\
\hline E Asian vs. SE Asian & 1.08 & $0.56-2.07$ & 1.30 & $0.55-2.86$ & 0.72 & $0.25-2.08$ & 1.29 & $0.79-2.12$ \\
\hline E Asian vs. S Asian & 0.78 & $0.35-1.74$ & 0.84 & $0.34-2.11$ & 0.25 & $0.08-0.84$ & 0.89 & $0.48-1.64$ \\
\hline
\end{tabular}

Odds ratio (OR) controlled for age, sex, education, and current insurance status

Mental Health Service Use Among Asian American

Subethnic Groups

In Table 4, multivariable logistic regression was used to compare the odds of mental health service use between East Asians versus Southeast Asians, and East Asians versus South Asians with mood disorders, anxiety disorders, substance use disorders, and any DSM-IV disorders. Models were adjusted for age, sex, education, and current insurance status. Compared to South Asians with substance use disorders, East Asians with had a significantly lower odds of mental health service use $(\mathrm{OR}=0.25$. $\mathrm{CI}=0.08-0.84)$. None of the other odds ratios for mental health service use were statistically significant. Except for substance use disorders, compared to Southeast Asians, East Asians had greater point estimates for the odds of mental health service use. Compared to South Asians, East Asians had lower odds of mental health service use in all mental disorder categories.

\section{Discussion}

The present study investigated the heterogeneity in the prevalence of mental disorders and use of mental health services among Asian Americans, especially concerning substance use disorders. Substance use disorders are highly comorbid with mood and anxiety disorders, and are predictors to suicidal thoughts and behaviors (Grant et al. 2005; Hasin et al. 2005). While previous studies reported that Asian Americans have a lower prevalence of psychiatric disorders and substance use disorders compared to other racial groups (Division 2011; Grant et al. 2005; Hasin et al. 2005, 2007), the present study demonstrated betweenAsian American subethnic group differences in mental health needs and service use patterns. We found that Southeast Asians had a higher prevalence of overall psychiatric disorders compared to East Asians and South Asians, mostly due to a high prevalence of drug use disorders. A higher prevalence of substance abuse and dependence among Southeast Asians may be due to having a higher proportion of recent migrants and refugees with pre-migration trauma and previous use patterns (D'avanzo 1997; O’Hare and Tran 1998). A large proportion of
Southeast Asian refugees from countries such as Cambodia, Vietnam, and Laos had been subjected to fear, trauma, and unfair treatment due to differences in ethnical, religious, or political opinions (Hsu et al. 2004). Post-migration stressors due to experience of discrimination and work-related stressors may increase problematic substance use behavior (Chae et al. 2008).

The prevalence and odds of mental health service use for any substance use disorder was especially low among East Asians compared to South Asians. This difference is consistent with the lower prevalence of mental health service use for depression reported among Chinese compared to Southeast Asians and South Asians in Canada (Tiwari and Wang 2008). Proximity and accessibility to care, availability of culturally and linguistically compatible mental health services, and practical and cultural acceptability of western psychiatry among underserved subethnic groups need to be further investigated. We found that East Asians and Southeast Asians are more likely than South Asians to reside in cities, which suggests that proximity to mental health services may not be the main reason for East and Southeast Asians' relative underuse of mental health services. Shared cultural perceptions on mental illness and mental health services, such as Chinese and Korean adults' tendency to normalize heavy drinking and accessing treatment as a last resort once criminal justice system made a referral (Park et al. 2010).

One of the main limitations of this study is small number of subjects with mental disorders and the lack of confidence in correctly capturing the distributions of mental health needs and mental health service use based on a more refined grouping (e.g., by specific countries of origin). We note that within-group differences in each of South, Southeast, and East Asian American subethnic categories may attenuate the between-group differences in the prevalence of mental disorders and service use. The NESARC data may not represent the current trend of mental health service use, since the data collection took place in 2001 and 2002. The NESARC study did not report response rate by nationality, and possible differences in response rates by Asian subethnic groups may compromise the internal validity of this study. Also, due to the reliance of self-report for ascertaining lifetime mental health service use, recall bias may have influenced our findings by under- 
reporting mental disorders. Furthermore, while Southeast Asian refugees are found to have a high level of posttraumatic stress disorders (PTSD)(O'Hare and Tran 1998), the NESARC wave 1 did not measure the prevalence of and service use for PTSD (Grant and Dawson 2006). The NESARC wave 2 assessed PTSD and found that Asian Americans had lower overall trauma exposure, but a higher prevalence of war-related trauma including experiences of being an unarmed civilian in a war zone or being a refugee (Roberts et al. 2011). The inclusion of a PTSD category could have increased the prevalence of anxiety disorders and service use among Asian subethnic group that experienced higher level of war-related trauma. Acculturation factors such as English proficiency that would have shed light on service use patterns were not measured for Asian Americans as part of the study.

Despite broadly classifying Asian Americans into three broad subethnic groups, our analysis found heterogeneity in the patterns of mental health service use across Asian American subethnic group categories. The strength of this study was that it examined the variability of mental health needs and service use patterns across Asian American subethnic groups using a methodologically strong, community-based dataset that is national in scope. The detailed, structured psychiatric interview and accompanying survey questions enabled the grouping of Asian American subethnic groups into South Asians, Southeast Asians, and East Asians, while such comparison across subethnic groups is rare in other smaller-scaled, community-based studies. Furthermore, the current study incorporated a structured assessment of psychiatric disorders and it allowed the analysis of treatment needs and service use patterns based on distinct categories of mental disorders.

There is significant heterogeneity in Asian Americans' mental health needs and service use patterns, especially among individuals with substance use disorders. Policy makers and service sectors should increase awareness about the fact that Southeast Asians, who are most impacted by substance use disorders, are in need of timely and culturally appropriate treatment. In addition, East Asians who have the least access to mental health services may need increased awareness and knowledge about substance use disorders and availability of services. Further studies on Asian American subethnic group differences in the role of pre-migration substance use patterns, acculturation, and social support on the use of alcohol and drugs in the United States will benefit the literature. Survey-based and intervention studies should ensure representation of diverse Asian American nationalities, and assess response rates and outcomes by countries of origin. More research is needed to investigate the barriers to mental health service use for substance use disorders including attitudes towards mental health services and availability of culturally sensitive services.
Conflict of interest Authors declare no conflict of interest.

\section{References}

Abe-Kim, J., Takeuchi, D. T., Hong, S., Zane, N., Sue, S., Spencer, M. S., et al. (2007). Use of mental health-related services among immigrant and US-born Asian Americans: results from the National Latino and Asian American Study. [Research Support, N.I.H., Extramural Research Support, U.S. Gov't, P.H.S.]. American Journal of Public Health, 97(1), 91-98. doi:10.2105/ AJPH.2006.098541.

Akutsu, P. D., Castillo, E. D., \& Snowden, L. R. (2007). Differential referral patterns to ethnic-specific and mainstream mental health programs for four Asian American groups. American Journal of Orthopsychiatry, 77(1), 95-103. doi:10.1037/0002-9432.77. 1.95.

American Psychiatric Association. (1994). Diagnostic and statistical manual of mental disorders (4th ed.). Washington, DC: American Psychiatric Association.

Anderson, R. N., \& John, F. (1973). Societal and individual determinants of medical care utilization in the United States. Milbank Memorial Fund Quarterly Journal, 51, 95-124.

Chae, D. H., Takeuchi, D. T., Barbeau, E. M., Bennett, G. G., Lindsey, J. C., Stoddard, A. M., et al. (2008). Alcohol disorders among Asian Americans: associations with unfair treatment, racial/ethnic discrimination, and ethnic identification (the national Latino and Asian Americans study, 2002-2003). Journal of Epidemiology and Community Health, 62(11), 973-979. doi:10.1136/jech.2007.066811.

D'avanzo, C. E. (1997). Southeast Asians: Asian-Pacific Americans at risk for substance misuse. Substance Use and Misuse, 32(7-8), 829-848. doi:10.3109/10826089709055861.

Gee, G. C., Spencer, M., Chen, J., Yip, T., \& Takeuchi, D. T. (2007). The association between self-reported racial discrimination and 12-month DSM-IV mental disorders among Asian Americans nationwide. Social Science and Medicine, 64(10), 1984-1996. doi:10.1016/j.socscimed.2007.02.013.

Grant, B. F., \& Dawson, D. A. (2006). Introduction to the national epidemiologic survey on alcohol and related conditions. Alcohol Research \& Health, 29, 74-78.

Grant, B. F., Hasin, D. S., Stinson, F. S., Dawson, D. A., June Ruan, W., Goldstein, R. B., et al. (2005). Prevalence, correlates, comorbidity, and comparative disability of DSM-IV generalized anxiety disorder in the USA: Results from the National Epidemiologic Survey on Alcohol and Related Conditions. [Research Support, N.I.H., Extramural]. Psychological Medicine, 35(12), 1747-1759. doi:10.1017/S0033291705006069.

Grant, B. F., Kaplan, K., Shepard, J., \& Moore, T. (2003a). Source and accuracy statement for wave 1 of the 2001-2002 National Epidemiologic Survey on Alcohol and Related Conditions. Bethesda, MD: National Institute on Alcohol Abuse and Alcoholism.

Grant, B. F., Moore, T., \& Kaplan, K. (2003b). Source and accuracy statement: Wave 1 National Epidemiologic Survey of Alcohol and Related Conditions (NESARC). Bethesda, MD: National Institute on Alcohol Abuse and Alcoholism.

Grant, B. F., Stinson, F. S., \& Dawson, D. A. (2004). Prevalence and co-occurence of substance use disorders and independent mood and anxiety disorders: Results from the National Epidemiologic Survey on Alcohol and Related Conditions. Archives of General Psychiatry, 61, 807-816.

Hasin, D. S., Goodwin, R. D., Stinson, F. S., \& Grant, B. F. (2005). Epidemiology of major depressive disorder: Results from the National Epidemiologic Survey on Alcoholism and Related 
Conditions. [Comparative Study Research Support, N.I.H., Extramural Research Support, Non-U.S. Gov't Research Support, U.S. Gov't, P.H.S.]. Archives of General Psychiatry, 62(10), 1097-1106. doi:10.1001/archpsyc.62.10.1097.

Hasin, D. S., Stinson, F. S., Ogburn, E., \& Grant, B. F. (2007). Prevalence, correlates, disability, and comorbidity of DSM-IV alcohol abuse and dependence in the United States: Results from the National Epidemiologic Survey on Alcohol and Related Conditions. Archives of General Psychiatry, 64(7), 830-842. doi:10.1001/archpsyc.64.7.830.

Hsu, E., Davies, C. A., \& Hansen, D. J. (2004). Understanding mental health needs of Southeast Asian refugees: historical, cultural, and contextual challenges. [Historical Article Review]. Clinical Psychology Review, 24(2), 193-213. doi:10.1016/j.cpr.2003.10. 003.

Hu, T. W., Snowden, L. R., Jerrell, J. M., \& Kang, S. H. (1993). Public mental health services to Asian American Ethnic Groups in two California Counties. Asian American and Pacific Islander Journal of Health, 1(1), 79-90.

Humes, K., Jones, N. A., \& Ramirez, R. R. (2011). Overview of race and Hispanic origin: 2010. 2010 Census Briefs: United States Census Bureau.

Lee, S. Y., Martins, S. S., Keyes, K. M., \& Lee, H. B. (2011). Mental health service use by persons of Asian ancestry with DSM-IV mental disorders in the United States. [Research Support, N.I.H., Extramural]. Psychiatric Services, 62(10), 1180-1186. doi:10. 1176/appi.ps.62.10.1180.

Masood, N., Okazaki, S., \& Takeuchi, D. T. (2009). Gender, family, and community correlates of mental health in South Asian Americans. [Research Support, N.I.H., Extramural Research Support, U.S. Gov't, P.H.S.]. Cultural Diversity Ethnic Minority Psychology, 15(3), 265-274. doi:10.1037/a0014301.

O'Hare, T., \& Tran, T. V. (1998). Substance Abuse Among Southeast Asians in the US. Social Work in Health Care, 26(3), 69-80. doi:10.1300/J010v26n03_05.

Park, S.-Y., Shibusawa, T., Yoon, S. M., \& Son, H. (2010). Characteristics of Chinese and Korean Americans in outpatient treatment for alcohol use disorders: Examining heterogeneity among Asian American subgroups. Journal of Ethnicity in Substance Abuse, 9(2), 128-142. doi:10.1080/15332641003772660.

Roberts, A. L., Gilman, S. E., Breslau, J., Breslau, N., \& Koenen, K. C. (2011). Race/ethnic differences in exposure to traumatic events, development of post-traumatic stress disorder, and treatment-seeking for post-traumatic stress disorder in the United States. [Research Support, N.I.H., Extramural]. Psychological Medicine, 41(1), 71-83. doi:10.1017/S0033291710000401.

Ruan, W. J., Goldstein, R. B., Chou, S. P., Smith, S. M., Saha, T. D., Pickering, R., et al. (2008). The alcohol use disorder and associated disabilities interview schedule-IV (AUDADIS-IV): Reliability of new psychiatric diagnostic modules and risk factors in a general population sample. Drug and Alcohol Dependence, 92(1-3), 27-36. doi:10.1016/j.drugalcdep.2007.06. 001.

Sentell, T., Shumway, M., \& Snowden, L. (2007). Access to mental health treatment by English language proficiency and race/ ethnicity. Journal of General Internal Medicine, 22(Suppl 2), 289-293. doi:10.1007/s11606-007-0345-7.

The Kaiser Family Foundation. (2008). Race, Ethnicity, Health Care: Fact Sheet. www.kff.org: Asian \& Pacific Islander American Health Forum.

Tiwari, S. K., \& Wang, J. (2008). Ethnic differences in mental health service use among White, Chinese, South Asian and South East Asian populations living in Canada. Social Psychiatry and Psychiatric Epidemiology, 43(11), 866-871. doi:10.1007/ s00127-008-0373-6.

United Nations Statistics Division. (2011). Composition of macro geographical (continental) regions, geographical sub-regions, and selected economic and other groupings. Retrieved October 15, 2011, from http://unstats.un.org/unsd/methods/m49/m49 regin.htm\#asia.

U.S. Census Bureau. (2011). 2010 Census shows America's diversity. Retrieved January 7th, 2010, from http://www.census.gov/news room/releases/archives/2010_census/cb11-cn125.html.

U.S. Department of Health and Human Services. (2001). US surgeon general releases report on mental health: Culture, race, and ethnicity. Public Health Reports, 116(4), 376.

Xu, Y., Okuda, M., Hser, Y.-I., Hasin, D. S., Liu, S.-M., Grant, B. F., et al. (2011). Twelve-month prevalence of psychiatric disorders and treatment-seeking among Asian Americans/Pacific Islanders in the United States: Results from the National Epidemiological Survey on Alcohol and Related Conditions. Journal of Psychiatric Research, 45(7), 910-918. doi:10.1016/j.jpsychires.2010. 12.009 . 